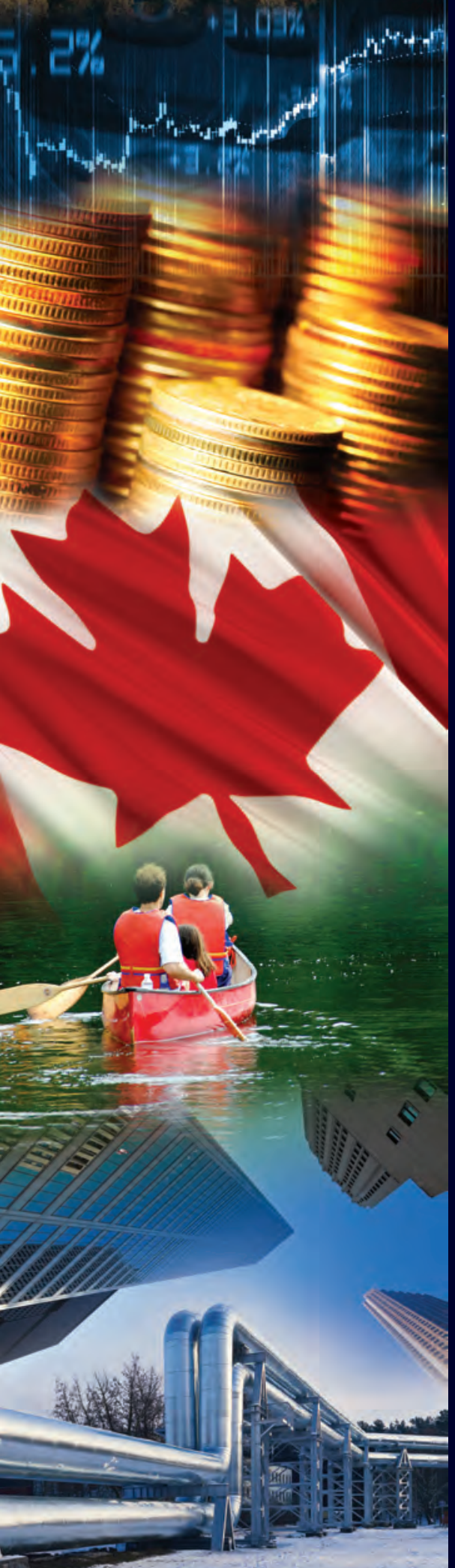

institut C.D. HOWE institute

COMMENTARY

NO. 446

\title{
Moving Parts: \\ Immigration Policy, Internal Migration and Natural \\ Resource Shocks
}

Recent changes to Canadian immigration policy, including the Temporary Foreign Worker Program, are positive overall. But they could have negative consequences that need addressing.

Michel Beine, Robin W. Boadway and Serge Coulombe 


\section{THE INSTITUTE'S COMMITMENT TO QUALITY}

\section{ABOUT THE AUTHORS}

Michel Beine

is Full Professor in

International Economics at the University of Luxembourg.

Robin W. Boadway

is Emeritus Professor of

Economics at Queen's

University.

Serge Coulombe is Full Professor at the Department of Economics, University of Ottawa.

Commentary No. 446 Immigration Policy
C.D. Howe Institute publications undergo rigorous external review by academics and independent experts drawn from the public and private sectors.

The Institute's peer review process ensures the quality, integrity and objectivity of its policy research. The Institute will not publish any study that, in its view, fails to meet the standards of the review process. The Institute requires that its authors publicly disclose any actual or potential conflicts of interest of which they are aware.

In its mission to educate and foster debate on essential public policy issues, the C.D. Howe Institute provides nonpartisan policy advice to interested parties on a non-exclusive basis. The Institute will not endorse any political party, elected official, candidate for elected office, or interest group.

As a registered Canadian charity, the C.D. Howe Institute as a matter of course accepts donations from individuals, private and public organizations, charitable foundations and others, by way of general and project support. The Institute will not accept any donation that stipulates a predetermined result or policy stance or otherwise inhibits its independence, or that of its staff and authors, in pursuing scholarly activities or disseminating research results.
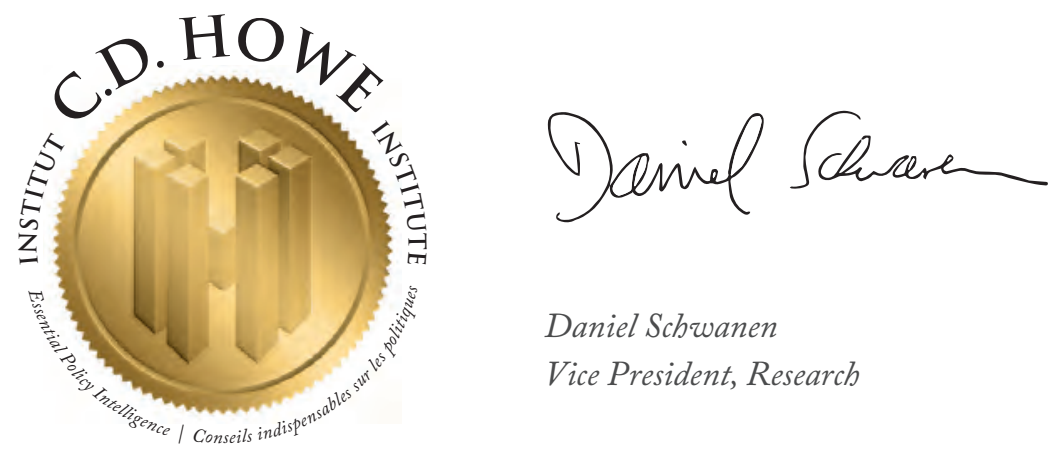

Daniel Schwanen

Vice President, Research 


\section{THE STUDY IN BRIEF}

The Canadian government made major changes in 2014 to both the Temporary Foreign Worker (TFW) Program and the permanent economic immigration system. Under the previous system and its enforcement, temporary foreign workers were in competition with some Canadian residents, resulting in a major political backlash. In addition, permanent immigrants to Canada were not generally moving to locations with the strongest demand for jobs.

The federal changes to the TFW Program limited the kinds of workers companies could bring in, made the applications more rigorous, and set an employer-specific cap on the use of TFWs. These changes will lead to a decrease in the number of TFWs working in Canada.

In the permanent immigration system, the government modified the traditional points system and created the Express Entry System. International applicants must meet a threshold of points before the government will invite them to apply for immigration. The system is skewed toward labour-market demand. It rewards workers who have skills that the federal government determines the labour market needs. It also rewards permanent immigrants who have a Canadian job offer.

We expect that the changes to the permanent immigration system will have many positive results. Immigrants will have better skills and improved job-market outcomes, and they will meet employer needs more closely than permanent immigrants did in the past. Likewise, recent changes to the TFW Program will improve the labour market for existing residents.

However, the changes in the immigration system may have some unintended consequences. First, they make it difficult for international students at Canadian universities to become permanent residents. Further, whereas TFWs were the main source of labour-market competition for Canadian residents until 2014, new permanent immigrants will increasingly compete with Canadian residents. This change will have profound implications for interprovincial migration. Lastly, the permanent immigration policy prioritizes skills currently in demand, and that preference may decrease the immigration of workers whose skills may be more important in the longer term.

Although, on the whole, the recent changes are an improvement to Canadian immigration policy, the federal government should consider addressing these potential negative consequences as it moves forward with its reforms. Those refinements would entail:

- better incorporating recent international graduates of Canadian universities into the permanent immigration system;

- creating more permanent immigration opportunities for immigrants with skills the Canadian economy may need in the future, although they are not in demand in today's labour market; and

- addressing the concern that permanent international immigrants will reduce the incentive for Canadian residents to move among the provinces to seek better opportunities.

All things considered, in terms of substituting for existing Canadian workers, we argue that the new immigration system will make TFWs less attractive and permanent immigrants more competitive.

C.D. Howe Institute Commentary (C) is a periodic analysis of, and commentary on, current public policy issues. Rosemary Shipton and James Fleming edited the manuscript; Yang Zhao prepared it for publication. As with all Institute publications, the views expressed here are those of the authors and do not necessarily reflect the opinions of the Institute's members or Board of Directors. Quotation with appropriate credit is permissible.

To order this publication please contact: the C.D. Howe Institute, 67 Yonge St., Suite 300, Toronto, Ontario M5E 1J8. The full text of this publication is also available on the Institute's website at www.cdhowe.org. 


\section{In the past two years, the Canadian federal government has implemented changes to policies governing the entry of both temporary foreign workers (TFWs) and permanent immigrants.}

Although the new rules have not yet been tested and many details need to be fine-tuned, we argue that the changes to both the permanent immigration system and TFW policies are substantial. These changes will have the effect of matching immigrants better to current employer needs and will improve the labour market for existing Canadians. However, the changes may have the unintended consequence of sacrificing the long-term immigration needs of the Canadian economy.

Migration - both international and interprovincial - is critical to the way the Canadian economy responds to economic shocks. Canada is a decentralized federation, with sparsely populated regional resource economies subject to upswings and downswings because of gyrations in the world prices of commodities. Migration to and from the resource-poor but population-rich parts of the country is key to spreading the effects - both positive and negative - of resource booms and busts across the country.

Before the changes to our immigration policy framework in 2014, permanent immigrants in Canada did not seem to respond to market signals such as booms and busts in regional economies. In contrast, TFWs and interprovincial migrants responded strongly, especially by locating close to employment opportunities. Consequently, TFWs became substitutes for interprovincial immigrants, whereas permanent immigrants did not. The recent changes to immigration policy are likely to alter these patterns.

We are interested in the interaction of temporary and permanent migration with internal labour markets. To the extent that immigrants are used to meet the increased demand for labour when provinces are booming, potential migrants from the rest of Canada are discouraged from moving to seek higher wages and do not benefit from the resource boom via the migration mechanism. The additional supply of immigrant labour also mitigates wage increases that would otherwise occur as a result of the boom. Once the boom is over and the labour demand subsides, Canada may be left with a surplus of immigrant workers in that region.

\section{Immigration Policy Changes}

In changing its immigration policy, the federal government has modified the traditional points system and created the Express Entry System. International applicants must meet a threshold of points before the federal government will invite them to apply for permanent immigration. The system is skewed toward labour-market demand. It rewards workers who have skills that the federal

The authors thank Benjamin Dachis of the C.D. Howe Institute and several anonymous reviewers for comments on earlier drafts. They retain responsibility for any remaining errors and the views expressed. 
government determines the labour market currently needs. It also rewards permanent immigrants who have a Canadian job offer.

The federal changes to the TFW Program limit the kinds of TFWs companies can bring into the country, make the applications more rigorous, and set an employer-specific cap on the use of TFWs. These changes will lead to a decrease in the number of TFWs working in Canada.

Although, on the whole, the recent changes are an improvement to Canadian immigration policy, the federal government should consider addressing the potential negative consequences as it implements its reforms. Those refinements would entail:

- better incorporating recent international graduates of Canadian universities into the permanent immigration system;

- creating more permanent immigration opportunities for immigrants with skills the Canadian economy may need in the future, although they are not in demand in today's labour market; and

- addressing the concern that permanent international immigrants will reduce the incentive for Canadian residents to move among the provinces to seek better opportunities.

\section{THE PREVIOUS IMMIGRATION SYSTEM AND LABOUR MARKETS IN CANADA}

By their nature, but also because of different immigration policies, the three migration flows we study in this Commentary - interprovincial migrants, TFWs, and permanent immigrants exert different outcomes on the local labour market. We argue that, before the recent reforms, most permanent immigrants, including those selected through the Federal Skilled Worker Program, were not market and employer driven, in contrast to most of the TFWs.

The number of permanent international immigrants has steadily increased since the mid1990s, with slightly more than 250,000 entering the country in 2014. The number of TFWs grew rapidly during the same period and peaked in 2009 at 191,000 per year (Figure 1). Since then, the number of TFWs has averaged about 175,000 per year.

\section{Temporary Foreign Workers}

TFWs coming into Canada through the various TFW programs are meant to be temporary additions to the labour force and, therefore, market and employer driven. Their recruitment is subject to a set of labour-market tests carried out by Employment and Social Development Canada (ESDC) and by immigration authorities. ESDC required these tests for 38 percent of the total TFWs admitted to Canada in 2012 (Worswick 2013). The purpose of the tests is to ensure that the vacant job allocated to a specific TFW cannot be filled by an existing Canadian worker located in the vicinity (see Worswick 2013 and Gross 2014). ${ }^{1}$ When their employment is over, as in seasonal employment, TFWs must return to their country of origin. Unless they are skilled workers, TFWs are not allowed to come with dependents. In general, the typical duration of a TFW position is for one year, and it can be renewed once.

Certain TFW programs are not necessarily demand driven - the International Experience Canada Program, for example, and the permits issued to spouses of foreign nationals in highskilled occupations. Based on a survey of all

1 Labour Market Opinion (LMO) tests were in place until the end of 2014. Following the changes in the TFW program, LMO tests were replaced by the Labour Market Impact Assessment (LMIA) tests, which follow the same objective of avoiding the displacement of existing Canadian workers by incoming TFWs. 


\section{Figure 1: Migration Flows in Canada}

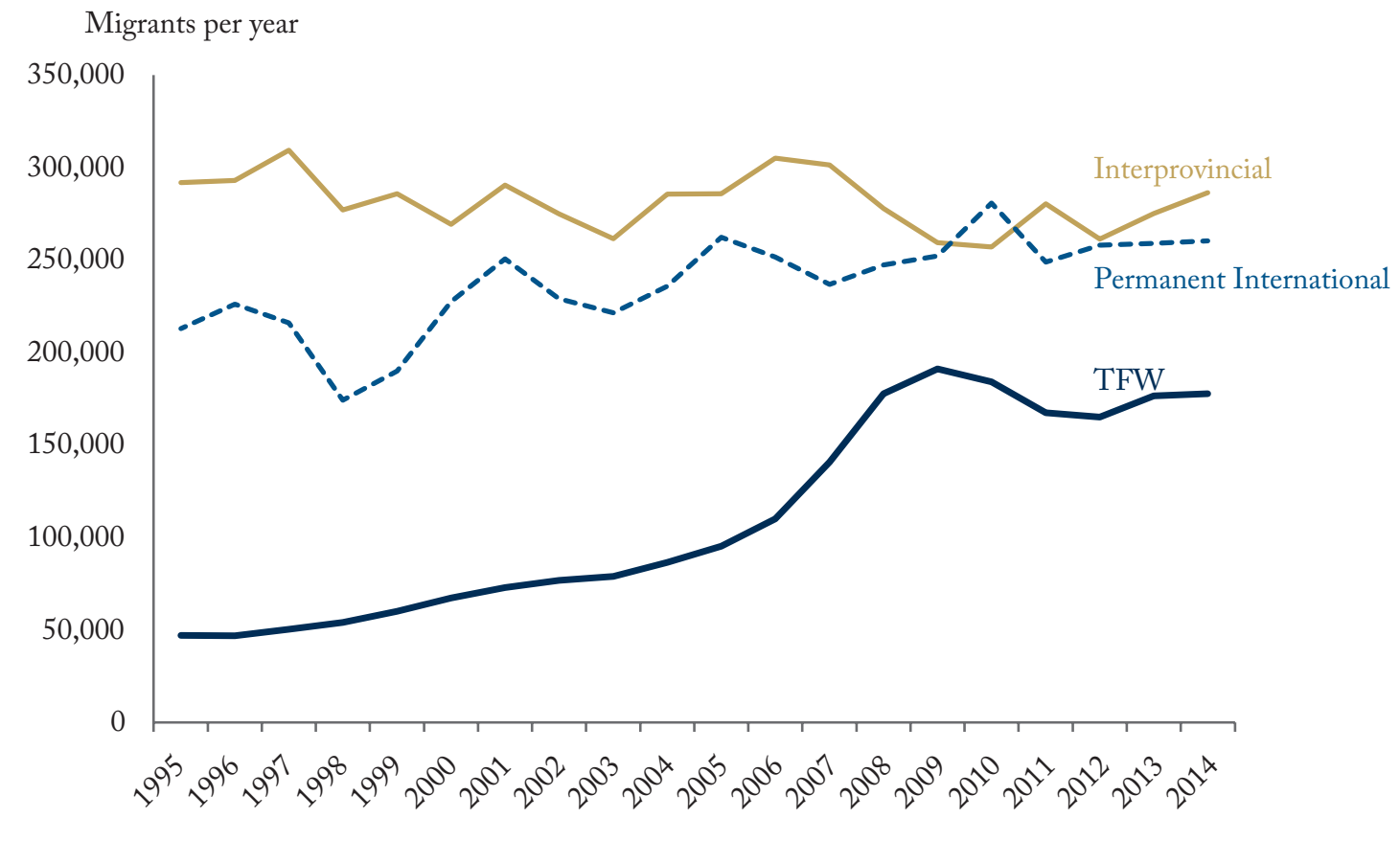

Source: Citizenship and Immigration Canada (CIC), Facts and Figures 2014.

categories in the TFW programs before the recent reform and the application of conservative assumptions, we estimate that about 65 percent of TFWs are market-driven immigrants. ${ }^{2}$

\section{Permanent Migrants}

Permanent migrants coming into Canada can be divided in three classes: economic migrants, family reunification migrants, and refugees. Clearly, the immigrants coming from the family and the refugee classes are immigrant driven in the sense that the process is initiated by immigrant applications rather than by employers. Before the recent changes to immigration policy, most of the economic immigrants who came to Canada through the Federal Skilled Worker Program were immigrant driven. The federal government selected these workers under the point system that allocated points based on a screening of personal characteristics such as age, education, and language proficiency. For the other categories of economic

2 Working from Worswick (2013), Table 2, we evaluate whether each category of the TFWs is demand driven or not. The categories subject to LMO evaluations (38\%) are obviously demand driven. Among the others, the two types of TFWs that are less likely to be demand driven are those coming under the Canadian Experience Program (students from Canadian institutions) and spouses of skilled workers. 
migrants (Canadian Experience Class, Provincial Nominees, Live-in Caregivers, and Skilled Trades), the classification between demand-driven and immigrant-driven migrants was less clear cut. Nevertheless, all those categories also included dependents (spouses and children) that were clearly not demand driven. All in all, making conservative assumptions and using the 2014 breakdown of flows of economic migrants (see CIC, Facts and Figures 2014), we estimate that only 9.9 percent of all permanent immigrants could be identified as demand driven. ${ }^{3}$

Furthermore, it is important to note that most economic immigrants coming from the Provincial Nominee Programs (PNP) were demand driven. Seidle (2013) shows that most of them were initially admitted to Canada as TFWs, even though there were differences across the provinces. The TFW Program seemed to be the main channel of market- and employer-driven immigration in Canada before the recent reforms.

When admitted to Canada before 2014, permanent immigrants lived wherever they wanted and did not have to go to booming areas where labour shortages had been observed. The admitted candidates could also bring their relatives under the accompanying family scheme. They tended to concentrate in big cities such as Toronto, Vancouver, and Montreal, where they found a strong diaspora. (See Beine, Docquier, and Özden 2011 on the network effect.)
Permanent economic immigrants (including Federal Skilled Workers, family reunification migrants, and refugees) reported around 61 percent participation rate in the job market in December 2014, compared with around 67 percent for the Canadian born. ${ }^{4}$ This difference can be explained by three key factors: the mismatch between the skills of the immigrants and vacant jobs; the corresponding mismatch for their family members; and the fact that they were free to move anywhere, including to areas with excessive labour supply.

One of the principal differences between the Express Entry System for permanent immigrants introduced in January 2015 and the previous system is the way the pool is managed. In the former point system, applicants who got more than the minimum number of points were put in a pool, and the government issued invitations to immigrate to Canada based on a first-come, first-served basis. With the new system, immigration offers will be made to the top-ranked candidates in the pool. The other main difference affecting the probability of being selected is the much greater importance of a job offer from a Canadian employer (see below for more details on the new system). With these changes, the permanent immigrant selection process becomes much more demand driven.

The interprovincial migrant channel is largely demand driven: the prospect of finding a better job is clearly an important motivation for moving. However, Canadians migrate to another province

3 To estimate this share, we identified how many of the 2014 permanent immigrants (260,000 in total) we could reasonably classify as demand driven. We classified family-class immigrants as immigrant driven. Within the economic immigrants, we could also considered the dependents as immigrant driven. Among the principal permanent immigrant applicants, three classes could be considered as (partly) demand driven: the Canadian Experience Class, the Live-in Caregivers, and the Provincial Nominees. Considering that these immigrants were all demand driven (a conservative assumption), at most 47,000 permanent immigrants could be considered as demand-driven immigrants.

4 Data on the participation of immigrants in the labour force in this essay are taken from the Labour Force Survey. We report the last number before the changes to the permanent immigrant system in early 2015. 
for other reasons too, such as better geographic amenities or to take advantage of improved education and health services at a lower tax rate (see Boadway and Flatters 1982 for a discussion of fiscally induced migration).

\section{MIGRATION FLOWS AND THE CANADIAN INDUSTRIAL STRUCTURE}

The extraction of a natural resource (such as oil and gas, minerals and potash) is geographically located in the area where the resource is found. Frequently, the site is in the hinterland of lesspopulated provinces, far from major labour markets. As a result, resource booms are characterized by temporary labour shortages for a wide variety of skills in the extraction area.

Companies have to find ways to attract workers from non-booming areas to migrate to the booming area. The resulting competition puts upward pressures on wages in both areas. Because of tight conditions in the labour market, it would be difficult for a regional economy with a booming natural resource sector to produce other traded goods to be exported to other regions of the country and the rest of the world. Consequently, a booming area will typically be characterized by a non-diversified industrial base (fewer manufacturing goods and other traded products) and a large service (or non-traded) sector. This phenomenon was termed the "Dutch disease" in an influential article in The Economist in 1977.

As long as the natural resource sector is booming, the lack of diversification of the booming economy is not a problem for overall economic well-being. Promoting diversification of the industrial base might even decrease economic well-being in the short term. Diversification nevertheless provides some insurance to the local economy for the period when the resource boom is over.

The first channel of transmission of the Dutch disease is related to the scarcity of labour - what has been called the "resource movement effect" (see Corden and Neary 1982). Labour will move from the trade-exposed manufacturing sector to the resource and service sectors, thereby pushing up wages. The second channel, called the "spending effect," goes through the exchange rate. Natural resources are traded in international markets, and a resource boom, driven by higher prices for the resource and/or the discovery of new reserves, generates an increase in domestic demand for non-traded goods and services and leads to an overall improvement in the terms of trade for the economy. In a floating exchange-rate regime, the rate will appreciate, resulting in a weakening of the competitiveness of the trade-exposed manufacturing sector.

With the recent substantial drop in oil prices and the depreciation of the Canadian dollar, many observers of the Canadian economy expect stronger growth in Canadian manufacturing sectors. This phenomenon might be viewed as a reverse Dutch disease. If some of the loss in manufacturing production is irreversible, however, this sudden change may not undo all the original effects of the Dutch disease.

\section{Migration and Dutch Disease}

In a recent study, Beine, Coulombe, and Vermeulen (BCV 2015) analyze how various migration channels might mitigate the effect of the Dutch disease at the provincial level in Canada. First, they demonstrate that the resource windfall tends to decrease the relative size of the manufacturing sector in the resource-rich provinces. Next, they estimate in the empirical analysis to what extent the Dutch disease effect is mitigated by the introduction of migration flows. They consider three migration channels: permanent immigrants selected under the point system, TFWs, and interprovincial migrants.

According to this empirical analysis, each of the three migration flows has a different impact on the effect that a resource boom has on the relative 
size of the booming province's manufacturing sector. Consequently, part of the regional Dutch disease in Canada is alleviated by the inflow of TFWs and interprovincial migrants in booming provinces. These migrants relieve pressure on the local manufacturing sector by preventing the wage rate from rising. From a booming province's policy perspective, both these immigration channels are efficient market mechanisms for promoting diversification.

BCV (2015) show that the effect of TFWs and interprovincial migrants in lessening the regional Dutch disease can be substantial. In Alberta from 2002 and 2009, for example, 50-60 percent of the regional Dutch disease was alleviated by the combined TFW and interprovincial migration channels.

When the resource boom is over, interprovincial migrants may return to their province of origin, and the need for TFWs will fade away. BCV (2015) show that, due to the entry of TFWs and interprovincial migrants during the boom, the Alberta economy has been better prepared to withstand the sharp decrease in the price of oil since the end of 2014. The use of workers from other provinces and other countries has contributed to diversifying the booming resource economy. Without the entry of these workers, the Dutch disease might have crippled most other industrial activities outside the booming resource sector and the associated economic activities.

Although both TFWs and interprovincial migrants appear to react to the same market signals in relation to a resource boom, they can also be substitutes or complements in labour markets, as we see below.

\section{TEMPORARY FOREIGN WORKERS, PERMANENT MIGRANTS, AND COMPETITION WITH CANADIANS}

Beine and Coulombe (2014) analyze empirically the possible competition for jobs between Canadian residents and both incoming TFWs and permanent international migrants under the previous immigrant selection system. By Canadian residents, we mean not only the Canadian born but also former immigrants who have integrated into the Canadian labour force. ${ }^{5}$ Beine and Coulombe (2014) specifically analyze the impact of TFWs and permanent immigrants on interprovincial migration in Canada. In this section, we highlight their key results. ( Details of their estimation techniques are presented in online Appendix A.)

Beine and Coulombe (2014) estimate a migration model across provinces and over time where the interprovincial migration rate (both net and gross migration) is potentially determined by the permanent international immigrants rates (economic class), the TFW rates, and a set of other control variables. Tables 1 and 2 summarize the results for the effect, respectively, of TFWs and permanent immigrants on interprovincial migration.

The key result demonstrated in Table 1 is that the impact of TFWs on interprovincial migration flows is negative and highly significant. The implication, then, is that TFWs are substitutes for interprovincial migrants. The inflow of TFWs into a province decreases the migration of Canadians into (increases it out of) the province. If the impact of TFWs had been positive and significant, TFWs would have been a complement to Canadian workers. If TFWs are neither substitutes nor complements for Canadian workers, the estimated impact of TFWs would not have been significant.

5 We define interprovincial migrants to include former permanent immigrants who arrived in one province, filled out at least one income tax report in that province, and moved to another province later on. 
Table 1: Quantitative Effects of 100 TFWs on Interprovincial Migration Flows

\begin{tabular}{lcc}
\hline & Short Run & Long Run \\
\hline All migrants & -53 & -182 \\
\hline 18-64 both sexes & -59 & -200 \\
\hline 18-24 both sexes & -113 & -349 \\
\hline 25-44 both sexes & -70 & -233 \\
\hline 45-64 both sexes & -35 & -125 \\
\hline 18-24 males & -133 & -344 \\
\hline $\begin{array}{l}\text { 18-24 females } \\
\text {-94 }\end{array}$ & -257 \\
\hline $\begin{array}{l}\text { Note: All results are significant at the 1 percent level. } \\
\text { Source: Beine and Coulombe (2014), Table 5. The figures } \\
\text { can be interpreted as the impact of 100 additional incoming } \\
\text { TFW in one given province on the number of net } \\
\text { interprovincial immigrants of each type in that particular } \\
\text { province. }\end{array}$
\end{tabular}

The impact of TFWs on interprovincial migration is not only negative and significant but substantial, too. Beine and Coulombe (2014) estimate that 100 additional TFWs arriving in a given province over one year reduces the net inflow of about 53 existing Canadian workers to this province in that year (Table 1, first column). This figure reflects the sum of two effects, one in terms of reduced immigration, and the other in terms of increased outmigration. Take, for example, TFWs landing in Ontario. First, TFWs create more competition with existing Canadian workers, who, on average, find it more profitable to leave Ontario - the traditional displacement effect. Second, TFWs landing in Ontario might deter prospective internal migrants from other parts of Canada coming to settle in Ontario. In this model, the direct displacement effect explains 40 percent of the
Table 2: Quantitative Effects of 100 Permanent Migrants on Interprovincial Migration Flows

\begin{tabular}{lcc}
\hline & Short Run & Long Run \\
\hline All migrants & $-16^{*}$ & $-55^{*}$ \\
\hline 18-64 both sexes & $-19^{*}$ & $-66^{*}$ \\
\hline 18-24 both sexes & -33 & -103 \\
\hline 25-44 both sexes & $-23^{*}$ & $-79^{*}$ \\
\hline 45-64 both sexes & $-10^{* *}$ & -103 \\
\hline 18-24 males & -34 & -94 \\
\hline 18-24 females & -34 & \\
\hline $\begin{array}{l}\text { Note: }{ }^{* *} \text { indicates that the effect is significant at the } \\
\text { that the effect is not statistically significant at even the } \\
\text { 10 percent level. }\end{array}$ & \\
\hline
\end{tabular}

net effect, while the reduction in gross provincial migration contributes to 60 percent of the net effect.

The results for the 18-24 year olds show that the young are more than twice as responsive to the presence of TFWs as the overall population. In terms of intergenerational equity, this number is important and has significant implications for the dynamics of the Canadian labour market. Job opportunities in other provinces are particularly important for young workers from depressed regions.

Beine and Coulombe (2014) also provide an estimate of the long-run effect of the entry of TFWs on interprovincial mobility (for more details, see online Appendix A). While the short-run effects are interpreted as the impact on flows within the year, the long-run effect captures the impact on the stock of interprovincial migrants - when flows have fully adjusted to the initial increase of 
incoming TFWs. They estimate that for 100 TFWs arriving in a given province every year indefinitely (and leaving after the year), the effect translates into a decrease in the stock of net migrants in the receiving province by 182 people. The long-run effect is larger than one for one (182/100) because the arrival of TFWs might prevent potential interprovincial migrants from moving with their spouses and dependents.

The long-run effect of TFWs refers to a situation in which an economy uses TFWs in response to a permanent shock. In that case, the sustained use of $100 \mathrm{TFW}$ s every year prevents the (net) arrival of a stock of 182 internal migrants. The long-run effect does not strictly apply to a resource economy where TFWs are used as a buffer to alleviate the temporary impact of booms and busts on the labour market. Obviously, resource windfalls are subject to shocks that are temporary but that display some effects over time. The long-run effect provides a benchmark beyond the pure short-run effect.

Beine and Coulombe (2014) also find that permanent immigrants do not have a robust and significant effect on the displacement of Canadian residents. In Table 2, the impact of permanent migrants on interprovincial migration flows is negative but not very significant. The potential impact of permanent migrants is also not very substantial. They estimate that 100 additional permanent migrants arriving in a given province over one year prevents the net inflow of about 16 existing Canadian workers (Table 2). For 100 permanent migrants arriving in a given province, that translates into a decrease in the stock of net migrants in the receiving province by 55 people.

Permanent immigrants, in contrast to TFWs, respond less to market signals. The TFW Program is mainly an employer-driven migration system, whereas the permanent immigrant channel is mainly an immigrant-driven system. These findings suggest that the profile of the immigrants, the way they are selected, and their capacity to fill vacant jobs in the Canadian labour market are key determinants of the degree of substitution with existing Canadian workers.

\section{EFFICIENCY AND EQUITY IMPLICATIONS OF TFWS IN A FEDERAL CONTEXT}

Some mechanisms - including federal-provincial fiscal transfers, individual tax transfer and social insurance systems, and interprovincial migration to booming regions - allow non-resource provinces to benefit from resource booms. Interprovincial migration transmits some of the benefits of the boom both to migrating workers and, because of the resulting increase in wage rates, to those who stay at home.

Before the immigration reforms that began to be implemented in 2015, the TFW Program was the main immigration tool used to alleviate labour shortages in booming regions. In effect, TFWs partly shut down one channel by which the internal labour market responds to a resource boom and spreads the benefits to other provinces. From an efficiency point of view, the TFW Program facilitates the expansion of resource and non-resource production in booming provinces by relieving excess demand for labour. Wage rates in the resource-rich provinces and also in other provinces will not rise as much as they otherwise would. TFWs might therefore mitigate the resource movement effect mentioned above. From that perspective, the TFW Program represents an advantage to resource-rich provinces in search of labour to fill a rapidly expanding economy.

At the same time, by offering an alternative to internal migration, TFWs reduce the market response of increased wages and employment to the excess demand for labour. The TFW Program therefore discourages the movement of interprovincial migrants in search of better incomes - something that is beneficial for migrants. Domestic migrants would gain not only higher salaries but also opportunities for training and 
experience that enhance their human capital. Although the TFW Program is helpful for the resource-rich provinces, it precludes some of the benefits of the resource boom from being spread to workers in the rest of Canada.

The adverse consequences of TFWs for internal migrants are mitigated by two considerations. First, if the resource boom is expected to be temporary, TFWs will prevent the possibly costly short-term internal migration of workers, many of whom return to their home province after the boom subsides. TFWs automatically return home after their work permits are finished. Second, resource booms can attract excessive internal migrants to the extent that provincial resource revenues are used to create preferential fiscal benefits both for migrants and through favourable business taxes for firms that create jobs for migrants (Boadway and Flatters 1982). TFWs can reduce excess fiscally induced migration from these two sources.

More generally, the benefits of TFWs can be judged in the context of the gainers and the losers among all stakeholders from the resource boom. If market adjustments are efficient, labour as a whole will stand to gain from the boom. The advantage is compromised, however, by labour-market and migration rigidities, especially those that result in involuntary unemployment in the non-resource provinces. But to the extent that the TFW Program suppresses wage increases in the booming region, a lower share of the benefits of the resource boom will accrue to Canadian workers, with a greater share going to capital owners, including the domestic and foreign owners of resource firms. Future generations are largely excluded, in particular because they will both forgo a share of resource rents and bear the costs of any environmental degradation that may occur.

\section{REFORMS OF THE IMMIGRATION SYSTEM}

\section{The Previous Permanent Immigration System}

The point system was introduced in 1967 in Canada to avoid potential discrimination in the immigrant selection process. ${ }^{6}$ The point system ignored, for example, the immigrant's country of origin.

Many empirical analyses in Canada have underlined the difficulty that permanent immigrants selected by the point system face in integrating into the Canadian labour market (see Bloom, Grenier, and Gunderson 1994). Some simple statistics reflect the relatively poor performance of permanent immigrants in the Canadian labour market. On average for 2014, the overall national participation rate for permanent immigrants was 61.6 percent, compared with 67.5 percent for the Canadian born. The percentage varies across provinces, but in some eastern provinces the employment rate fell below 60 percent. Again for 2014, the aggregate unemployment rate of permanent immigrants was 7.9 percent, compared with 6.6 percent for the Canadian born. ${ }^{7}$ These poor performances can be explained by several features related to the point system.

First, under the old point system, the valuation of points did not take into account the place where education was acquired. In general, this factor led to a discrepancy in the effective human capital level for the same nominal level of education between Canadian residents, on the one hand, and, on the other, the immigrants selected under the point system and their families. Coulombe and Tremblay (2009) used the results of standard literacy tests to compare the cognitive skills of Canadian residents with the cognitive skills of immigrants.

6 Green and Green (2004) provide a historical analysis of the Canadian immigration system.

7 Again we are using Labour Force survey data for 2014, the last year before the reform of the immigrant system. 
They found that, for a given level of schooling, immigrants selected from countries with a lower level of economic development had a lower level of cognitive skills than the Canadian born.

On average, the skill-schooling gap of immigrants corresponds to three years of schooling in Canada. Coulombe and Tremblay (2009) estimate that one-third of the gap was caused by language difficulties in English or French, and two-thirds could be imputed to a lower quality of schooling in countries with a lower development level. In their survey, Hanushek and Woessmann (2008) identify low quality of schooling as being as important a factor as the quantity (number of years of study) for explaining the low level of human capital in less-developed countries. In the new Express Entry System, candidates will be required to show an educational credential assessment by a designated party to make sure their credentials are in line with Canadian standards.

A second feature is that the old point system was close to a pure immigrant-driven system of immigration policy (Bertoli et al. 2012). The process is initiated by the immigrant, and the government assesses each candidate on the basis of his or her personal characteristics, such as education, age, and language proficiency. In contrast, the accumulation of points gives little importance to the propensity to match labour-market requirements as does a demand-driven immigration policy. The example of a pure demand-driven system is the H1B visa procedure prevailing in the United States. Under this system, the visa is granted only to the applicants who have been sponsored - who have received job offers from US employers. In the old Federal Skilled Worker System, candidates received 15 points out of 100 for a job offer. Nevertheless, given the way the pool was managed (first-come, first-served basis), this dimension played a minor role in the probability of being selected. As a result of the old point system in Canada, a large subset of permanent immigrants displays a significant skill mismatch with respect to labour-market needs.
A final reason for low participation rates and high unemployment rates is that the rates are computed for the whole category of permanent immigrants, not just the economic immigrants. This category includes refugees and the family class. These classes are clearly not market-driven immigrants, and they are less likely to work in Canadian labour markets.

\section{Major Changes to the Permanent Immigration System}

The new policy for permanent immigration introduces two important features that should correct, at least partially, some of the flaws of the old one. We do not provide here a full list of the new changes but discuss the most prominent features relevant for our analysis.

The first is the way the new Express Entry System works. Prospective candidates for permanent immigration need first to send the immigration authorities a self-declared statement of their characteristics. Using the Federal Skilled Worker ranking system, they are ranked in a pool, and the highest-ranked individuals receive an invitation to apply. The candidates who send in an application are then evaluated and ranked, using the new Comprehensive Ranking System (Table 3). This system takes into consideration factors such as age and education but also skill transferability factors such as language and work experience. Unless candidates receive a Provincial Nomination (which means in practice that they should already be in Canada), they need to get a job offer, validated by a positive Labour Market Impact Assessment, from a Canadian employer. The valid job offer gives 50 percent of the total points in the Comprehensive Ranking System (600 out of 1,200).We believe that it will be almost impossible for a foreign worker located outside Canada to enter through the new Express Entry System without a Canadian job offer. This restriction implies that the pool of successful candidates will have skills and work experience 


\section{Table 3: Ranking System for Permanent Immigrants - Proportion of Maximum Points per Category} over Total Points

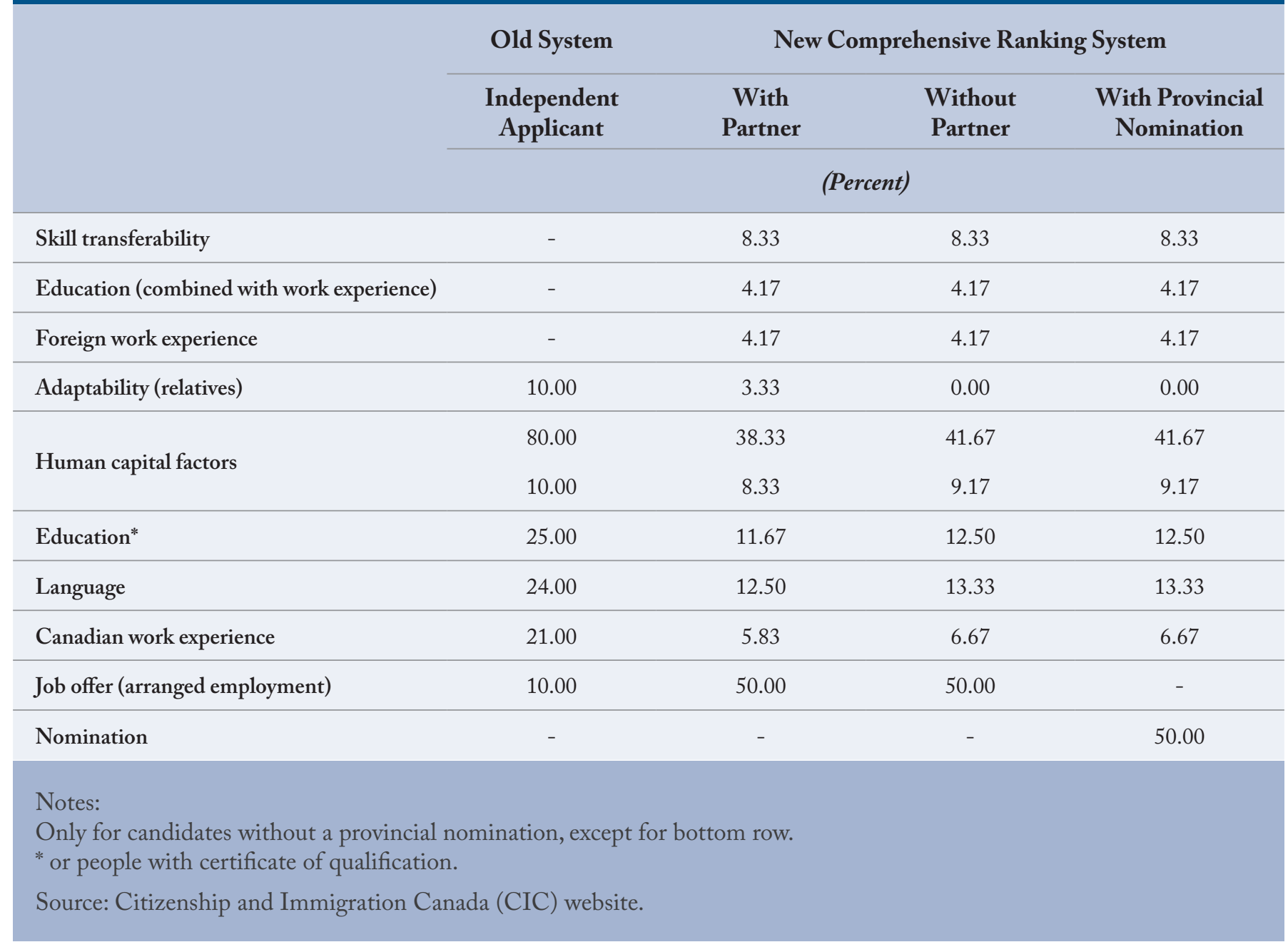

in occupations that are more in demand in the Canadian labour market.

The second important change concerns the way the pool of applicants is going to be managed. In the former point system, applicants who got more than the minimum number of points were put in an inventory: those who were invited to immigrate to Canada were determined on a firstcome, first-served basis. This system, combined with the existence of backlogs in the processing of applications, tended to result in a loss of good candidates, who migrated to other countries with a faster immigration process. Sometimes a prospective migrant stayed in the pool for a period of eight years. In contrast, under the new system, immigration offers will be made to the topranked candidates in the pool. Early results from the beginning of 2015 indicate that the Express Entry immigration process could operate within a minimum of two months.

These important changes suggest that the new point system will move from a mainly immigrantdriven immigration system to one that is equally employer-demand driven. The new system should also result in an overall increase in the level of human capital of immigrant workers, when human 
capital is measured, as in Coulombe and Tremblay (2009), by a direct measure of skills (test scores or wages) instead of years of schooling.

\section{Changes to the Temporary Foreign Worker Program}

The federal government made major changes to the TFW Program in 2014. These changes will alter the way TFWs interact with other categories of workers in the labour market and lead to a decrease in the number of TFWs working in Canada.

The first important change is the way the TFWs are split into different categories. In the old system, the different categories were distinguished on the basis of professional occupations. The new system will make a distinction based mostly on wage levels, with the exception of some particular occupations such as agriculture or live-in caregiving. In turn, some changes will introduce more stringent regulations, especially for low-wage TFWs.

Second, the reform will strengthen the procedure of the labour-market tests to make sure TFWs do not crowd out existing Canadian workers. This change will target low-wage TFWs in particular. Employers must follow a more rigorous procedure called the Labour Market Impact Assessment (LMIA): they will have to provide additional information, such as the number of people born in Canada that applied for the available job, the number of existing Canadians who were interviewed, and the reasons they were not hired. These measures aim at decreasing the crowding-out effects of TFWs on existing Canadian workers and making sure that existing Canadian workers come first in line.

The new LMIA will also make use of some improved labour-market information sent to existing Canadian workers, including new databases of job vacancies. For some categories such as highwage positions, Canadian employers must submit transition plans along with their LMIA application. These plans will include proposed investments to help existing Canadian workers to acquire the required skills in the vacant jobs through skills training or an apprenticeship program. Finally, the fee paid by employers for an LMIA will be raised from $\$ 275$ to $\$ 1,000$, meaning that the costs of the LMIA system will be borne almost entirely by employers.

Third, there will be a cap on the number of TFWs, especially in the low-wage category. After 2016, each employer will have to limit the proportion of TFWs to 10 percent of the workforce in each location of the firm. Furthermore, the duration of the work permit will be limited to one year instead of two years as before. Employers willing to hire low-wage TFWs will have to reapply every year for an LMIA. Finally, in order to decrease the dependency on TFWs in some sectors, the federal government will reduce the length of time a TFW in a low-wage occupation can work in Canada. All in all, these measures will lead to a significant decrease in the number of TFWs in the Canadian economy.

TFWs are also prohibited from working in some sectors located in high-unemployment areas. Immigration authorities will refuse to conduct LMIA tests in sectors such as the accommodation, food services, or retail trade sectors if the prevailing unemployment rate in the specific area exceeds 6 percent.

These measures will reduce the degree of competition and substitutability between TFWs and existing Canadian workers. They will also reduce the dependency of some sectors on TFWs and lead to a decrease of the overall number of TFWs working each year in Canada. As such, the overall crowding-out effects of TFWs on existing Canadian workers will tend to decrease.

\section{INTENDED AND UNINTENDED EFFECTS OF THE NEW REFORMS}

We expect that the new Express Entry System will have obvious economic advantages. The new immigrants will have generally higher skills than previous immigrants. Also, the degree of mismatch 
between their skills and labour-market needs should decrease. The responsiveness of permanent migrants to job opportunities such as those created by resource booms will also increase. Overall, this reform should lead to a better performance by permanent immigrants in labour markets.

Despite these positive developments, the Express Entry System will also have unintended negative effects.

First, the reforms may be detrimental to the immigration of some categories of prospective immigrants. One important category concerns international students who have studied in Canada. Inflows of foreign students have become increasingly important in many developed countries such as Canada. International students in Canada amount to around 200,000 and represent about 10 percent of total students in tertiary education institutions. They represent a valuable source of funding for universities since institutions tend to charge higher fees than the ones applied to resident students.

They also represent a kind of "disguised brain drain" since almost half of foreign students intend to stay and work in Canada after completion of their academic courses. They are furthermore endowed with skills that are more consistent with the needs of the domestic labour market. Unsurprisingly, given the increasing importance of that category of new immigrants in most developed countries, there is a growing academic literature devoted to the analysis of this important phenomenon. ${ }^{8}$

International students in Canada have the option of applying through the Provincial Nominee Program (PNP) or prospecting during their studies for valid job offers. It may be easier for potential immigrants who have studied in Canada to obtain job offers from Canadian employers for two reasons: it is an advantage during a job search to be located in the country, and potential employers may have greater confidence in the quality of a Canadian education. These potential migrants, no longer eligible for the TFW Program, will have to qualify for the Express Entry System, but a large subset of them will lack valid job offers that match the immigration system guidelines. Job offers are important during the two steps of application of the new Express Entry System. The uncertainty created by the new system might lower the probability to receive a valid job offer. In turn, this might lower the probability to either receive an invitation to apply or to be selected within the Comprehensive Ranking System.

In effect, then, the new system, while raising the economic adaptability of new economic immigrants, will hurt a valuable channel of immigration for Canada. International students educated in Canadian universities should, if they are accepted as immigrants, display a very good match between their skills and the needs of the Canadian labour market, with the added advantage that they should not face any real issues in integrating into the Canadian society.

Second, the new reform will increase the degree of substitution between new permanent immigrants and interprovincial immigrants. In other words, we should expect to have more negative and more significant numbers under the new regime. This result may be seen as negative because it will lead to a decrease in the internal mobility of existing Canadian workers - something that has always been considered a natural adjustment mechanism in a decentralized economy subject to significant asymmetric shocks. Given that new permanent immigrants can become Canadian citizens, however, it would not be reasonable to put less weight

8 See Beine, Noel, and Ragot (2015) for a cross-country analysis of the determinants of inflows of foreign students such as tuition fees, universities' academic quality or job prospects. 
on them than on internal migrants. Thus, the displacement of internal migrants by permanent immigrants may not be viewed in the same negative light as the displacement by TFWs.

Finally, by putting more emphasis on adaptability to current market conditions, the new system will decrease the capacity to attract people with skills that are currently disregarded but might be important in the long term. Current market imbalances are imperfect predictors of future booming sectors of the economy. Moreover, attracting skilled immigrants, irrespective of their degree of matching with current jobs, is a gamble that, in the future, they will create new economic opportunities in sectors that are currently difficult to predict. The point system has always been the tool for attracting talented people to Canada without too much consideration for current economic conditions and the capacity of the economy to absorb new immigrants (Green and Green 2004). Permanent immigrants also include entrepreneurs who can create further opportunities for Canadian workers beyond the skills they bring with them. Still, lowering the immigration flows of permanent immigrants during economic downturns may favour the convergence of earnings between immigrants and the Canadian born.

A related consideration is that current labour market conditions can be reversed in the future. For instance, resource booms are well known to be temporary in nature and to follow cycles - as in the recent sharp drop in oil prices. The issue, however, is that attracting immigrants on a permanent basis to fill up jobs that may well be temporary will have long-term problems when resource booms turn to busts. The advantage of hiring TFWs to fill these jobs is that, when the boom is over, these immigrants return to their country of origin. In contrast, permanent immigrants who lose their jobs after the boom will have to display a high degree of adaptability to move to alternative sectors of the economy.

With regard to the new changes in the TFW Program, we can consider them as positive developments, given the previous evidence of these immigrants crowding out existing Canadian workers. We should expect that, under the new regime, the impact of these TFWs on existing Canadian worker mobility will become less negative (see Table 1). In other words, the degree of substitution between TFWs and existing Canadian workers should decrease.

\section{Recommendations for Refining the New Reforms}

To sum up, the new immigration reforms should lead to a situation in which resident Canadian workers will be less in competition with TFWs but more competitive with permanent immigrants. Although, on the whole, the recent changes are an improvement in Canadian immigration policy, the federal government should consider addressing all the potential consequences as it moves forward with reforms in this area. These refinements will entail:

- finding ways to incorporate recent international graduates of Canadian universities into the permanent immigration system;

- creating more permanent immigration opportunities for immigrants with skills the Canadian economy may need in the future, although they are not rewarded in today's labour market; and

- addressing the potential impact that permanent international immigrants will have on the incentive for Canadian residents to move among the provinces.

\section{CONCLUSIONS}

This essay discusses the impact of some aspects of Canadian immigration policy under the previous regime. It also tries to forecast some of the consequences for Canadian regional economies of the changes introduced in 2015 regarding the TFW program and the immigration of new permanent immigrants. Permanent migrants have various advantages and disadvantages over temporary workers, and vice versa (Table 4). Governments 


\section{Table 4: Economic Advantages and Disadvantages of Migrant Types}

\begin{tabular}{|c|c|c|}
\hline & Advantages & Disadvantages \\
\hline TFWs & $\begin{array}{l}\text { - Reduce labour shortages in boom periods } \\
\text { - Allow diversification of regional economies } \\
\text { - Prevent inefficient internal migration } \\
\text { - } 100 \% \text { employment rate }\end{array}$ & $\begin{array}{l}\text { - Substitute for existing Canadian workers } \\
\text { - Reduce internal mobility of existing workers } \\
\text { - Decrease incentives for existing Canadians to } \\
\text { invest in some specific skills }\end{array}$ \\
\hline Permanent Migrants & $\begin{array}{l}\text { - Little displacement of existing Canadian workers } \\
\text { - In general, skilled immigrants bring overall } \\
\text { economic benefits (e.g., positive fiscal contribution) } \\
\text { - Contribute to the development of new sectors }\end{array}$ & $\begin{array}{l}\text { May not reflect short-term and potentially } \\
\text { long-term needs of economy } \\
\text { - Create pool of unemployed during resource } \\
\text { bust periods } \\
\text { - Low employment and participation rates }\end{array}$ \\
\hline
\end{tabular}

should consider these factors before making any further changes to current policy.

The previous immigration policy regime included distinctive features about the admission to Canada of TFWs as well as permanent immigrants through the point system. In short, the TFW Program was close to a pure demand-driven system, in which employers could easily fill up vacant jobs by bringing workers from abroad on a temporary basis. The point system, in contrast, was close to a typical immigrant-driven system, in which candidates for permanent immigration were screened and admitted on the basis of their personal skills and characteristics, with little attention to their capacity to match current labour requirements.

The previous system governing TFWs and permanent immigrants had both positive and negative consequences for Canadian regions. On the positive side, the admission of TFWs diversifies provinces, especially in resource-rich, boom regions. This outcome is important because booms are temporary in nature, as the current drop in oil prices exemplifies. The TFW Program was popular with provincial governments.
The previous permanent immigrant system gave considerable weight to a candidate's educational attainment, as opposed to having a current job offer. As a result, Canada admitted candidates with general skills. The thinking behind this policy was that workers with general skills would adapt to future changing needs in the labour market.

The old immigration regime nevertheless had flaws. The inflows of TFWs tended to reduce the mobility of Canadian workers across provinces. That in turn weakened a natural and historical channel of regional adjustments to asymmetric shocks occurring in Canada. By paying little attention to the mismatch between the skills of the admitted permanent immigrants and labour market needs, the old point system resulted in permanent immigrants' relatively high unemployment rates and low participation and employment rates.

\section{Canada's New Immigration System}

The combination of reforms in the admission of TFWs and permanent immigrants to Canada will have important economic consequences for 
the economy. First, the changes will reduce the inflow of TFWs and decrease the substitutability between foreign workers and Canadian workers. As a result, there may be an increase in the net mobility of Canadian workers from non-booming to booming regions.

This possible outcome has both positive and negative consequences. First, by raising the economic opportunities for Canadian workers, the unemployment rates in non-booming regions may be lowered. Young workers may have a chance to enter the labour market and acquire the professional experience they need for a successful career.

Second, the reforms in the point system will increase the human capital of new permanent immigrants and, possibly, their labour market performances. The new immigrants will be more able to fill vacant jobs - and more substitutable for existing Canadian workers.

Canadian workers will be more in competition with permanent immigrants than before, and less competitive with TFWs. The fact that permanent immigrants will be more inclined to take vacant jobs is a positive development.

Nevertheless, there will be downsides. First, in the case of temporary booms, filling vacant jobs with permanent workers instead of TFWs creates an intertemporal labour mismatch. Second, the new system, by putting too much emphasis on the match with current needs in the labour market, may reject candidates with skills that could turn out to be very useful in the future. Current market imbalances are imperfect predictors of the skills that will be needed in the long term. 


\section{REFERENCES}

Beine, M., C. Bos, and S. Coulombe. 2012. "Does the Canadian Economy Suffer from Dutch Disease?” Resource and Energy Economics 34(4): 468-92.

Beine, M., and S. Coulombe. 2014. "Immigration and Internal Mobility in Canada." CES Ifo Working Paper No. 4823, June.

Beine, M., S. Coulombe, and W.N. Vermeulen. 2015. "Dutch Disease and the Mitigation Effect of Migration: Evidence from Canadian Provinces." Economic Journal 125 (December): 1574-1615.

Beine, M., F. Docquier, and C. Özden. 2011. "Diasporas." Journal of Development Economics 95(1): 30-41.

Beine, M., R. Noel, and L. Ragot. 2014, "The Determinants of International Mobility of Students." Economics of Education Review, 41C, 40-54.

Bertoli, S., H. Brücker, A.M. Mayda, and G. Peri. 2012. "The Battle of Brains: How to Attract Talent." In Brain Drain and Brain Gain: The Global Competition to Attract High-Skilled Migrants. T. Boeri, H. Brücker, F. Docquier, and H. Rapoport (eds). Oxford: Oxford University Press.

Bloom, D. E., G. Grenier, and M. Gunderson. 1994. The Changing Labor Market Position of Canadian Immigrants. No. w4672. National Bureau of Economic Research.

Boadway, R, and F. Flatters. 1982. "Efficiency and Equalization Payments in a Federal System of Government: A Synthesis and Extension of Recent Results." Canadian Journal of Economics 15: 613-33.

Ciuriak, Dan. 2014. "Diagnosing Dutch Disease.” Discussion Paper, Ciuriak Consulting Inc., 18 December 2014. http://papers.ssrn.com/sol3/papers. cfm?abstract_id $=22540108$

Corden, W.M., and J.P. Neary. 1982. "Booming Sector and De-industralisation in a Small, Open Economy." Economic Journal 92: 825-48.
Coulombe, S., G. Grenier, and S. Nadeau. 2014. "Human Capital Quality and the Immigrant Wage Gap.” IZA Journal of Migration 3:14.

Coulombe, S., and J.F. Tremblay. 2009. "Migration and Skills Disparities across the Canadian Provinces." Regional Studies 43(1): 5-18.

Green, A.G., and D. Green. 2004. "The Goals of Canada's Immigration Policy: A Historical Perspective." Canadian Journal of Urban Research 13(1): 102-39.

Gross, D.M. 2014. Temporary Foreign Workers in Canada: Are They Really Filling Labour Shortages? Commentary 407. Toronto: C.D. Howe Institute. April.

Hanushek, E.A., and L. Woessmann. 2008. "The Role of Cognitive Skills in Economic Development.” Journal of Economic Literature 46(3): 607-68.

Krugman, P.R. 1991. Geography and Trade. Cambridge, MA: MIT Press.

Morissette, R., and H. Qui. 2015. "Interprovincial Employment in Canada, 2002 to 2011.” Statistics Canada. http://www.statcan.gc.ca/pub/11-626$\mathrm{x} / 11-626-\mathrm{x} 2015047$-eng.htm

Sachs, J.D., and A.M. Warner. 2001. "The Curse of Natural Resources." European Economic Review 45(4-6): 827-38.

Seidle, F.L. 2013. “Canada’s Provincial Nominee Immigration Programs: Securing Greater Policy Alignment." IRPP Study No. 43. December

Worswick, C. 2013. "Economic Implications of Recent Changes to the Temporary Foreign Worker Program." IRPP Insight 4. October. 
NOTES: 
NOTES: 


\section{ReCEnt C.D. Howe Institute Publications}

March 2016 Schwanen, Daniel. "National Priorities 2016 - At the Global Crossroads: Canada’s Trade Priorities for 2016.” C.D. Howe Institute E-Brief.

February 2016 Vegh, George. "Learning from Mistakes: Improving Governance in the Ontario Electricity Sector.” C.D. Howe Institute E-Brief.

February 2016 Bishop Grant, and Benjamin Dachis. "The National Energy Board's Limits in Assessing Upstream Greenhouse Gas Emissions.” C.D. Howe Institute E-Brief.

February 2016 Laurin, Alexandre. "The High Cost of Getting Ahead: How Effective Tax Rates Affect Work Decisions by Lower-Income Families.” C.D. Howe Institute E-Brief.

February 2016 Kronick, Jeremy. Looking for Liquidity: Banking and Emergency Liquidity Facilities. C.D. Howe Institute Commentary 445.

February 2016 Alexander, Craig. "Job One is Jobs: Workers Need Better Policy Support and Stronger Skills.” C.D. Howe Institute E-Brief.

January 2016 Anderson, Barry, and John Richards. Students in Jeopardy: An Agenda for Improving Results in Band-Operated Schools. C.D. Howe Institute Commentary 444.

January 2016 Blomqvist, Åke, and Colin Busby. "National Priorities 2016 - Challenging Vested Interests: National Priorities for Healthcare in 2016." C.D. Howe Institute E-Brief.

January 2016 Blomqvist, Åke, and Colin Busby. Shifting Towards Autonomy: A Continuing Care Model for Canada. C.D. Howe Institute Commentary 443.

January 2016 Benjamin Dachis. "National Priorities 2016 - Getting More Buildings for our Bucks: Canadian Infrastructure Policy in 2016.” C.D. Howe Institute E-Brief.

January 2016 Benjamin Dachis. “National Priorities 2016 - The Future of Canadian Energy Policy.” C.D. Howe Institute E-Brief.

December 2015 Dachis, Benjamin, William B.P. Robson, and Aaron Jacobs. "A Crisis of Capital: Canadian Workers Need More Tools, Buildings and Equipment” C.D. Howe Institute E-Brief.

December 2015 Schwanen, Daniel, Dan Ciuriak, and Jeremy Kronick. Opening up New Trade Routes for Financial Services: Canada's Priorities. C.D. Howe Institute Commentary 442.

\section{SUPPORT THE INSTITUTE}

For more information on supporting the C.D. Howe Institute's vital policy work, through charitable giving or membership, please go to www.cdhowe.org or call 416-865-1904. Learn more about the Institute's activities and how to make a donation at the same time. You will receive a tax receipt for your gift.

\section{A REPUTATION FOR INDEPENDENT, NONPARTISAN RESEARCH}

The C.D. Howe Institute's reputation for independent, reasoned and relevant public policy research of the highest quality is its chief asset, and underpins the credibility and effectiveness of its work. Independence and nonpartisanship are core Institute values that inform its approach to research, guide the actions of its professional staff and limit the types of financial contributions that the Institute will accept.

For our full Independence and Nonpartisanship Policy go to www.cdhowe.org. 

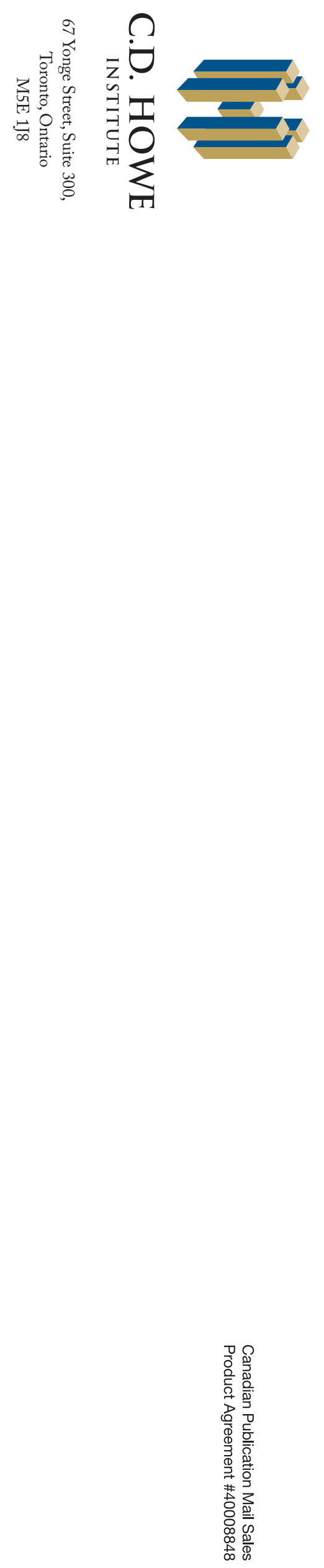